\title{
The effects of the online customer experience on customer loyalty in e-retailers
}

\author{
Mansoureh Zare*, Roya Mahmoudi
}

Department of Information Technology and Computer Engineering, Sabzevar Branch, Islamic Azad University, Sabzevar, Iran

\begin{abstract}
The modern world has seen significant growth in the e-commerce industry in terms of volume and acceptance among customers. E-commerce has changed the behavior of shoppers depending on various factors such as easy accessibility and availability of a wider range of products and services. Now, customer retention has become a challenge for any company because there is so much competition. This article seeks to further understand the online customer experience and examine the customer experience in online sales and its impact on customer loyalty. However, empirical research on online customer experience and loyalty is scarce. The aims of this study are unique to two cases. The first is to examine the effect of online customer experience on customer responses to e-commerce retailer Digikala in Iran, given that two dimensions of online customer experience including empirical and emotional states are considered as customer experience evaluation tools. Each of these two dimensions is about explaining customer loyalty. Customer Experience is a new field of competition for brands to create an effective customer experience. This is the key to distinguishing brand names from one another, and lacking appropriate solutions for managing the customer experience will affect all aspects of the business, given the importance of the online customer experience in loyalty and maintaining a competitive advantage. Research is important and can have beneficial implications for entrepreneurship and formulating organizational strategies.
\end{abstract}

Keywords_ Online customer experience, Electronic retail, Customer loyalty.

\section{INTRODUCTION}

Nowadays, customers are moving to virtual stores to benefit from lucrative offers and a better shopping experience. Because e-commerce has tremendous potential for current and futures markets, the Internet provides a unique platform for companies to more effectively reach existing and potential customers. In recent years, consumers have been using the internet to shop in the process before, during and after their online shopping. Advancement in mobile technology and adoption by many consumers, redesigning interaction features and delivering services to achieve the best online user experience is essential for companies[1].

So since customers started using Internet-enabled devices, there has been a significant increase in the change in shopping behaviors[2,1]Companies have to compete in an environment that deals with a variety of online channel formats, including e-commerce, social media websites. For example, customers view social networks, use their smartphones to visit corporate websites, and also use their computers to visit e-commerce sites at different times. Therefore, the online customer experience encompasses all the contact points (social media, website, apps) that the customer selects to interact with the company. Contemporary social networks or online social networks have provided the opportunity for corporate customers to diversify ideas and ideas to foster innovation[3,1]Offering unique experiences to clients and immersing them in the core areas of the Internet is one of the goals of today's web entrepreneurs. Consumers are increasingly sensitive to the mental and symbolic nature of commercial sites. They are looking for a product or service to look for a unique shopping experience[4].

The purpose of the present study is to compare the impact of online customer experience on the loyalty of digital ecommerce customers, which is the largest and most popular e-commerce retailer in Iran. The goals of this unique study include examining the impact of online customer experience 
on loyalty in a digital retailer. The comparative analysis is based on two dimensions of the online consumer experience assessment tool: empirical and emotional.Also, customer loyalty includes five dimensions of attitude loyalty complaint behavior - desire to be loyal - resistance to competitive bidding - situational loyalty. In this paper, first, the concepts discussed, the research hypotheses are presented. We then describe the method and present the main results. We will conclude by discussing findings, managerial implications, limitations, and research opportunities.

\section{THEORETICAL BACKGROUND AND DEVELOPMENT OF HYPOTHESES}

\subsection{Customer Experience}

The customer experience is the result of a combination of emotional or rational customer perceptions during any direct or indirect interaction with a business. As a result, knowing how successful you are in creating an effective, great and enjoyable customer experience will show you How much can you hope for the future of your business. In contemporary markets, e-commerce is no longer an auxiliary channel or strategy. It has become part of the strategy of public trade[1]In other words, any exchange of services, regardless of its nature and form, leads to the customer experience ,5]. [6Recent business practices also broadly define the customer experience as "encompassing all aspects of a company's offering" - quality customer care, as well as advertising, packaging, product and service features, ease of use and reliability[7]Customer experience is crucial in shaping customers' perceptions of online retailer's expectation[8].

\subsection{Online customer experience}

New developments in e-commerce and e-commerce technologies, along with the widespread use of mobile devices and social media, have enabled companies to enhance their customers' shopping experiences and interactions with brands anytime and anywhere.

The online shopping experience means that customers are increasingly relying on social communications, online recommendation engines and other enabling technologies to guide their buying and buying decisions and use more digital tools to facilitate their shopping activities[9 ,1].The Internet acts as a driving force in business initiatives, enabling entrepreneurs to develop a professional participatory culture that embraces the benefits of Internet technologies, best practices, and electronic consent and e-loyalty. And evaluate the impact of online trading on achieving sustainable competitive advantage[12-10].

Experts define the empirical state as the "component of online customer experience to knowledge or conscious mental processes" and the emotional state as a component of online customer experience that "involves the individual's emotional system through generational production"[13,11].

Portable devices are present in people's lives everyday. It represents unique opportunities for the service industry, utilizing various platforms to communicate and communicate online with an increasing number of customers. Technological advances in network communications, protocols, computers, and user interface design have led to the emergence of online publishing and e-commerce. Consumers today have access to vast stores of information from any location at any time. Therefore, the provision of this information should be tailored to the limitations of different devices (smartphones, tablets, PCs).

For example, psychological functions and factors have been identified as the main dimensions of the online customer experience. The online customer service experience is defined as "the customers' mental perception of interacting with a company's value proposition online. These perceptions in turn follow a set of outcomes, namely benefits, feelings, judgments, and intentions." Previous researchers have been trying to probe the possible outcomes of the online customer experience and have theoretically concluded that the intention to repurchase is one of the major consequences of enhancing the online customer experience[1].

\subsection{Customer Loyalty}

Businesses today are focusing more on maintaining and retaining existing customers, and attracting new customers comes second. Research shows that attracting new customers is 5 to 25 times more expensive than retaining current customers. In summary, we can say that loyal customer characteristics are:

Despite competitors' advertising, we prefer our products to other competitors, doing word-of-mouth marketing of the brand and defining our products in front of other customers, regularly purchasing our products, emotionally bonding with our brand.

Today, in line with the rapid growth of markets and technology, which is becoming new every day, the customer is one of the key factors for companies to survive and increase market share and profit. Companies are looking for 
loyal customers who can help the company achieve its goals. Customer loyalty and customer satisfaction are important factors in creating repeat purchases. Advances in Internet technology have increased the way companies communicate with customers. Modern corporate marketing strategy has gradually shifted from traditional profits to customer orientation. Thus, customer loyalty is a key factor for companies to enhance their competitive power [7] Loyal customers are more inclined to buy more products, pay less attention to product prices, and introduce the brand to their family and friends[14]

\section{RESEARCH BACKGROUND}

Bilgihan et all. (2016)- have presented a study titled "Towards a unified customer experience in online shopping environment" They developed a theoretical model for a seamless customer experience by drawing on consumer behavior literature in online texts, and the findings of this article suggest that it is easy to find a website/program, ease of use, usefulness, features Utility, perceived enjoyment, personalization, social interactions, and multi-device compatibility are components of the integrated online customer experience. Brand interaction, positive word of mouth (WOM) and frequent shopping are compelling results of the online customer experience[1].

Lin and Bennett. (2014)- have presented a study titled" Examining retail customer experience and the moderation effect of loyalty programs" the research has been conducted to develop a comprehensive customer experience design using constructive actions in the supermarket and Chinese department stores. They found that the experimental results of the model confirmed the effect of customer experience on customer satisfaction and loyalty. But it shows that loyalty programs play a small role in strengthening the bonds in the model[15].

Brun, Isabelle et al.(2017)- have presented a study titled" Impact of customer experience on loyalty: a multichannel examination" Exploring the Relationship Between Five Dimensions of Customer Experience This experiment focuses on two different channels, namely physical branch and online A total of 484 responses were managed in a webbased survey on banking experience. This exercise was subsequently repeated in the tourism sector. The findings show that the main dimension affecting fidelity is the (negative) dimension, so it plays an important role in the empirical marketing literature because negative emotions are rarely examined[16].

\section{RESULTS ANALYSIS METHOD}

In this paper, the effect of customer experience on customer loyalty is examined The required information was obtained through questionnaires. The methodology of the present research is to investigate the status quo in terms of what has been achieved and the researcher is not allowed to do any manipulation to the independent variables, but we can use the research findings to suggest or design a model. Therefore, it can be said that this research is a descriptive study based on the way the data is obtained and since the data are collected through community sampling to examine the distribution of characteristics of the statistical society, this research is from the survey branch. It is also an applied research if we consider the goal. An applied research is an attempt to respond to a real and scientific problem that exists in real world.

So this research, according to the descriptive nature and the defined purpose, is of the applied type and the basis of how to do it is surveying.From the methodological point of view of data collection, the research method of this study is quantitative. The questionnaire tool is used to collect the required data (and is cross-sectional in time) as it examines the data available at the study site for a limited time. And has no long-term goal.Descriptive research describes and interprets what is, and focuses on existing conditions or relationships, common beliefs, current processes, visible effects, or expanding trends. Its focus is primarily on the present. However, it often takes into account past events and works that relate to existing conditions In most statistical activities, it is not enough to collect, adjust and present findings or determine statistics, but it is necessary to analyze and make inferences based on this collected and analyzed information. This part of the statistic, which relies on the analysis, interpretation, and generalization of the results of statistical preparation and computational calculation, is called inferential statistics. Using inferential statistics methods, the characteristics of the statistical population can be deduced from the sample.The statistical population of this research is the online retailers of Digikala in Iran. The sample size was 111 units using a random one-way regional clustering method.Also in this research software estimation method was used to estimate sample size using G POWER software.The indices required to estimate the sample in this 
software include Type I error 0.05 Type II error (at least equal to or 20\%), the average impact factor (at least 0.10 ) and test type appropriate to the hypothesis raised ( Structural equation modeling (test power) has been used.

The following are the hypotheses of this study:

- H1The online customer experience in retail has a positive impact on customer loyalty.

- H2The experimental dimension of online customer experience has a positive effect on online customer experience.

- H3The emotional dimension of online customer experience has a positive effect on online customer experience.

The statistical population of this study is all Digi Kala retail customers in Iran.Since the present study is a survey in terms of implementation, a researcher-made questionnaire has been used to collect information. And Randall Tale's Custonner Loyalty Questionnaire, which has five dimensions, is considered: Attitudinal loyalty- Complaint behavior- the desire to be faithful - Resistance to competitive offer- Resistance to competitive offer Situational loyaltyand Two empirical and emotional dimensions for online customer experience Is consideredDue to the subject variables and the relationship between the research components, the required data were collected in the research Since in the design of the questionnaire paying attention to the scale and the defined spectrum is necessary in order to convert the quality indices into measurable quantitative indices, therefore, in order to quantify the qualitative variables, the relative scale and Likert scale will be used.The scales in the Likert spectrum ranging from 1 to 5 with definitions of very low, moderate, high and very high will be given to the responders.

Credibility or validity refers to the rational connection between the test questions and the measured subject. When it is said that the test is valid, it means that the test questions accurately measure what is desired. In this study, content validity ratio (CVR) is used and the value of CVR is 0.8 based on 10 experts which is larger than 0.62 . So the questionnaire has content validity.

Reliability depends on, how much the instrument gives the same results under the same condition. To calculate the reliability coefficient of the measurement tool, different methods are used. In this study, to examine the reliability of the tool, Cronbach's alpha coefficient is used. The alpha coefficient indicates that the questions were overlapping and aligned, and the responders answered the questions with care and awareness. In a test with research objectives, the closer is the Cronbach's alpha index to 1 , the more is internal consistency between the questions and consequently questions will be more homogeneous.Cronbach proposes $45 \%$ reliability coefficient as low, $75 \%$ as moderate and acceptable, and 95\% as high. The results of the Cronbach's alpha test are shown in Table 1. Based on the results from Cronbach's alpha test, the value of all variables is more than 0.7 so the questionnaire has an acceptable reliability.

Table 1 - Cronbach's alpha test results

\begin{tabular}{|c|c|}
\hline Dimension & Cronbach's alpha \\
\hline Attitudinal loyalty & 817.0 \\
\hline Complaint behavior & 716.0 \\
\hline The desire to be faithful & 797.0 \\
\hline Resistance to competitive offer & 855.0 \\
\hline Situational loyalty & 844.0 \\
\hline Experimental & 733.0 \\
\hline Emotional & 771.0 \\
\hline
\end{tabular}

According to the results of the Cronbach's alpha test, the values of all variables are greater than 0.7 , so the questionnaire has acceptable reliability. After determining the validity and reliability of the questionaires, it was provided to Digikala retail customers electronically.

\section{DISCUSSION}

According to Figure 1, all variables of dimensions have star coefficients and are higher than the standard figure of 1/96, so in the next step, none of the dimensions will be removed from the model and all cases will be approved .Also, according to the output coefficients in this criterion in endogenous variables, the model entered in the circle of variables of Figure 2, all of which are above 33.3, so the criterion of R Squares coefficient is moderate and acceptable. 


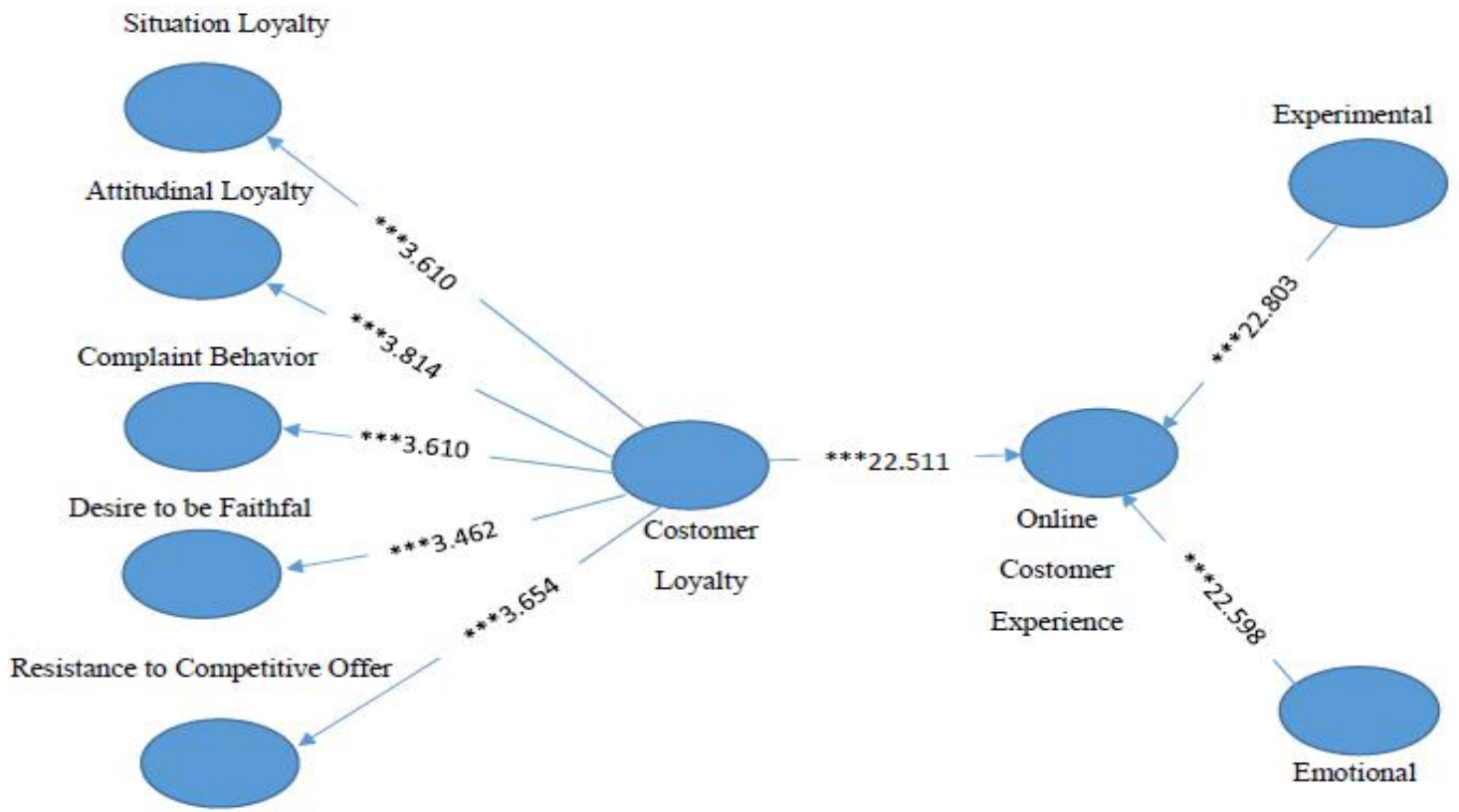

Fig.1: Examination of significance coefficients
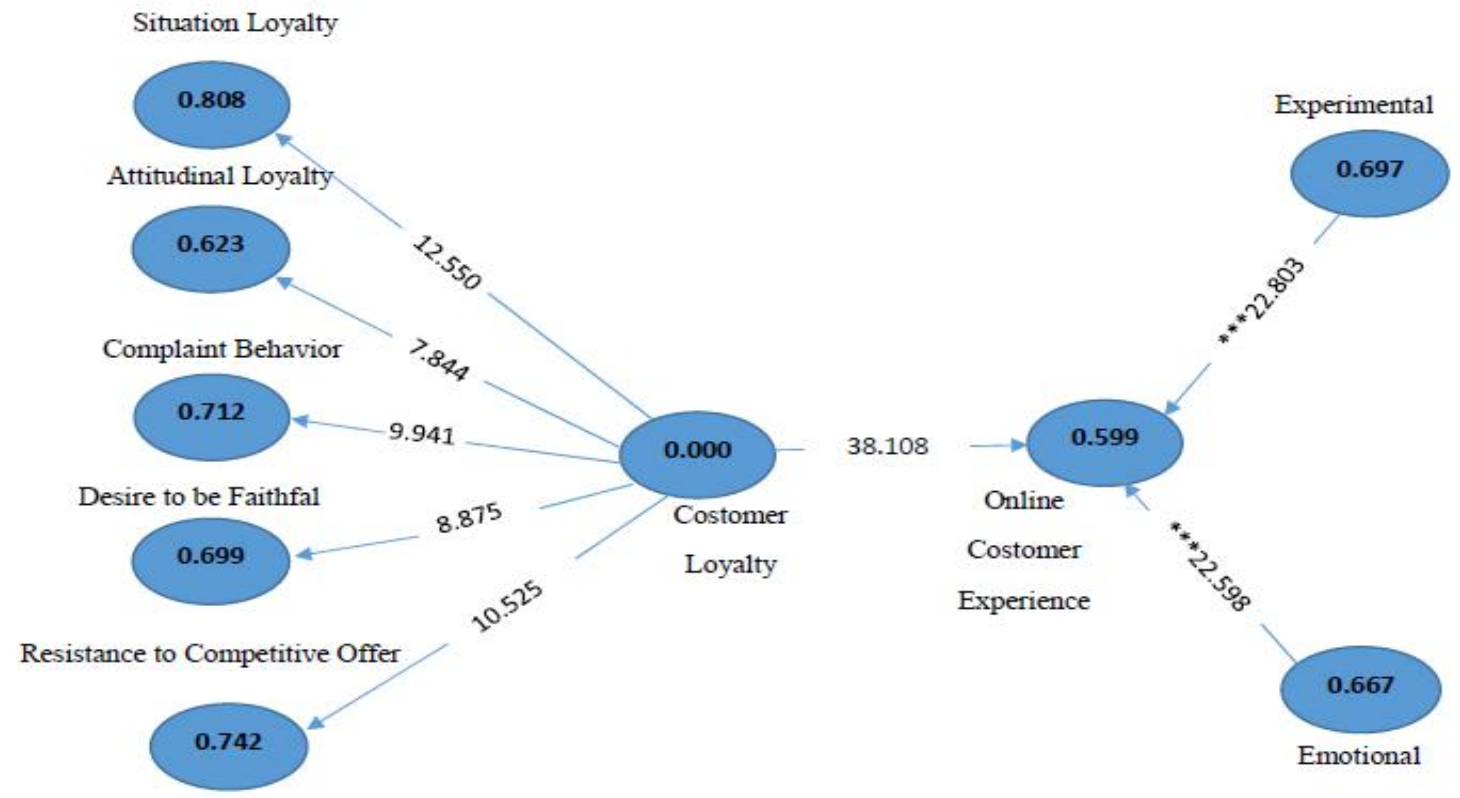

Fig.2: Examines standard path coefficients

\section{CONCLUSION}

In the recent online marketplace, customers are communicating with e-retailers using their computers, tablets and smartphones. They also interact with other customers using other social networking websites, thus providing unique experiences for clients to the benefit of web entrepreneurs.Researchers and web entrepreneurs have expressed particular interest in the online customer 
experience and have agreed on its importance in creating satisfaction, revising purchase intentions, e-trust and eloyalty. Digital interaction and communication shape the ecommerce scene. Consumers have different electronic devices. They keep their smartphones close to them and check them regularly. Many brands and businesses are trying to use the digital landscape to meet their customers' expectations in e-commerce $[17,1]$.

As a result of the dramatic changes in online shopping and the way customers interact with e-retailers, researchers, business owners and retailers are keen to understand the factors that create a compelling online user experience. Once the availability and core needs are met, users expect a compelling experience.Business owners need to keep in mind that due to poor online customer experience in ecommerce, a significant amount of potential revenue is lost globally. E-commerce companies must retain customers by providing compelling online experiences Therefore, this study aimed to investigate the effect of online customer experience in the field of online retail. In this study, we selected the largest online retail in Iran for review Launched in 2006, Digikala sells only digital and electronic goods online until it switches from digital sales to digital sales for two years, and then to the store. Online merchandise became available in all commodity categories.Included in the digital goods store can be digital buyers, cosmetics, health care, automotive, office \& supplies, fashion \& apparel, home \& kitchen services, books, arts \& crafts, toys, personal and Also mentioned as well as sports and travel. The DigiKala Supermarket has also been added to the collection in the summer of July, with Rockwell joining the collection. Most products have descriptions, reviews, and users can share their views, ratings and reviews of each product with other users.

Positive emotions and a compelling online experience help companies gain competitive advantage. To create a positive user experience, both usefulness and enjoyment must be a part of the experience of all users.

When purchasing goods from the store, the time it takes to get the product purchased by the customer is determined, the gift can be sent to your friends via digital commodity, there are amazing discounts and so on. The relationship with this online retailer seems to be getting the attention of its owners.

Based on the results of this research, the findings are as follows:

According to Figure 1, given that there is a significant relationship between customer loyalty and online magnetic experience at $99.99 \%$ confidence level (three stars equal to 22.511 and the first type of error allowed 0.1), so it can be so $\mathrm{He}$ said that the online customer experience in Digi Kala online retail has an effect on customer loyalty and therefore the first hypothesis is confirmed.

Given that there is a $99.99 \%$ confidence level between the experimental dimensions with the customer's online experience (three stars equal to 22.803 and the first error of the first type 0.1), so it can be said that the experimental dimension on the customer's online experience It has an effect and it affects it. Therefore, the second hypothesis is confirmed.

Given that there is a $99.99 \%$ confidence level between the emotional dimension of the customer's online experience (three stars equals 22.598 and the error of type 0.1), it can be thus described as the emotional dimension of the customer's online experience. It affects it.

Therefore, considering all three hypotheses in this study, business owners should design their business strategies for the online customer experience so that the customer improves both emotionally and empirically and becomes loyal customers for the business. Online shopping in crossborder e-commerce has become an integral part of our daily lives .Most people are looking for a good deal and good service when shopping, and this is very important to ensure the fairness of the service. This study confirms the significant positive effects of online customer experience on customer loyalty. In other words, customers who receive their desired services will receive a positive shopping experience and show their loyalty.Some of the benefits of customer loyalty in e-commerce organizations are as follows: The more loyal customers, the harder it is for competitors to enter and the less market share they will have. Also a very important concept for businesses is customer lifetime value. The Lifetime Value Index allows companies to predict their most profitable customer groups, which are actually loyal customers, rather than focusing on less profitable customers. Focus on them. There will be a surcharge and a supplement sale.

Upselling is a sales strategy where you can get customers to pay more for the services they need. For example, the customer is going to buy a suit and has $\$ 100$ in it, but at the store he persuades the seller to choose another suit that is worth \$200 and that the customer agrees to accept the seller's offer. Slow.Another technique is Cross Selling, where the services and products related to the requested product are 
also offered to the customer. For example, in a suit, the seller recommends that the buyer buy a suit and tie with the suit of his choice.These methods are much more effective for loyal customers because they know and trust their favorite brand and are easier to satisfy. Had. They have already figured out what salespeople are doing and what their company is worth and as a result there will be a much shorter sales cycle.

The more loyal customers a business has, the easier it is to anticipate their needs. In this case, the business knows its customer better and can better plan its future needs and needs. Compare this with a new customer whose company is not yet familiar with their needs and does not know their lifestyle.The likelihood that a customer who has made a double purchase will also make the next purchase is 9 times higher than a new customer. These figures show that if efforts are made to maintain and retain current customers, they will be far less costly. When customers are loyal to the brand they are more flexible about price increases and more comfortable with price increases and changes.

Future research should seek to replicate current research frameworks elsewhere to explore cross-sectional gaps. The limitations of this study include the timeframe for the research, and the likelihood of replicating this research on other companies may yield other results.

\section{REFERENCES}

[1] A. Bilgihan, J. Kandampully, and T. C. Zhang, "Towards a unified customer experience in online shopping environments," International Journal of Quality and Service Sciences, 2016.

[2] G. Wagner, H. Schramm-Klein, and S. Steinmann, "Effects of cross-channel synergies and complementarity in a multichannel e-commerce system-an investigation of the interrelation of e-commerce, m-commerce and IETVcommerce," The international review of retail, distribution and consumer research, vol. 23, no. 5, pp. 571-581.2013,

[3] H. Oinas-Kukkonen, Humanizing the web: change and social innovation. Springer, 2013.

[4] A. Carù and B. Cova, "How to facilitate immersion in a consumption experience: Appropriation operations and service elements," Journal of Consumer Behaviour: An International Research Review, vol. 5, no. 1, pp. 4-14, 2006.

[5] B. Schmitt, J. J. Brakus, and L. Zarantonello, "From experiential psychology to consumer experience," Journal of Consumer Psychology, vol. 25, no. 1, pp. 166-171, 2015

[6] K. N. Lemon and P. C. Verhoef, "Understanding customer experience throughout the customer journey," Journal of marketing, vol. 80, no. 6, pp. 69-96, 2016.
[7] C. Meyer and A. Schwager, "Understanding customer experience," Harvard business review, vol. 85, no. 2, p ,116 . .2007

[8] Y. Okada et al., "Genetics of rheumatoid arthritis contributes to biology and drug discovery," Nature, vol. 506, no. 7488, pp. 376-381, 2014.

[9] C. M. Cheung, I. L. Liu, and M. K. Lee, "How online social interactions influence customer information contribution behavior in online social shopping communities: a social learning theory perspective," Journal of the Association for Information Science and Technology, vol. 66, no. 12, pp. 2511-2521, 2015

[10] N. J. Vickers, "Animal Communication: When I'm Calling You, Will You Answer Too?," Current Biology, vol. 27, no. 14, pp. R713-R715, 2017.

[11] A. E. Micu, O. Bouzaabia, R. Bouzaabia, A. Micu, and A. Capatina, "Online customer experience in e-retailing: implications for web entrepreneurship," International Entrepreneurship and Management Journal, vol. 15, no. 2, pp. 651-675, 2019.

[12] A. Capatina and E. Rancati, Key challenges and opportunities in web entrepreneurship. IGI Global, 2017.

[13] C. Gentile, N. Spiller, and G. Noci, "How to sustain the customer experience:: An overview of experience components that co-create value with the customer," European management journal, vol. 25, no. 5, pp. 395-410, 2007.

[14] Y. Bai, S. Jia, S. Wang, and B. Tan, "Customer Loyalty Improves the Effectiveness of Recommender Systems Based on Complex Network," Information, vol. 11, no. 3, p. 171, 2020.

[15] Z. Lin and D. Bennett, "Examining retail customer experience and the moderation effect of loyalty programmes," International Journal of Retail \& Distribution Management, 2014.

[16] I. Brun, L. Rajaobelina, L. Ricard, and B. Berthiaume, "Impact of customer experience on loyalty: a multichannel examination," The Service Industries Journal, vol. 37, no. 5-6, pp. 317-340, 2017.

[17] R. Murtagh, "Mobile nowexceeds pc: The biggest shift since the internet began," Search Engine Watch, vol. 8, 2014. 